\title{
Are You Tired of “Us?” Accuracy and Bias in Couples' Perceptions of Relational
}

\section{Boredom}

Kiersten Dobson ${ }^{1}$, Sarah C. E. Stanton², Rhonda N. Balzarini ${ }^{3}$, \& Lorne Campbell ${ }^{4}$

1Department of Human Development and Family Studies, University of Illinois at Urbana-Champaign

2Department of Psychology, University of Edinburgh

${ }^{3}$ Department of Psychology, York University

${ }^{4}$ Department of Psychology, University of Western Ontario

\section{Author Note}

This research was supported by a Canada Graduate Scholarship awarded to Kiersten Dobson by the Social Science and Humanities Research Council (SSHRC) of Canada; an Ontario Graduate Scholarship awarded to Sarah C. E. Stanton by the Ministry of Colleges and Universities of Canada; and an Insight grant awarded to Lorne Campbell by SSHRC.

The authors gratefully acknowledge Paige Bastow for her assistance with Study 1 data collection, and Madison Corkery, Alexa Momy, Madison Loder, Nicole Zouki, Jenney Zhu, Lora Yurdakul, Batool Azra, Alia Hussain, and Claudia Czechowski for their assistance with Study 3 data collection. The authors declare no conflicts of interest with respect to the authorship or publication of this article.

Direct correspondence to Kiersten Dobson, University of Illinois at UrbanaChampaign, Department of Human Development and Family Studies, 222 Bevier Hall, 905 S. Goodwin Ave, Urbana, IL 61801. Email: kdobson@illinois.edu

Word Count (including Abstract, Main Text, References, Foot/Endnotes): 9,771

Tables: 6

Figures: 5
References: 42 


\begin{abstract}
Relational boredom is an important but understudied area of the relationship maintenance literature. In three dyadic studies, we investigated the interplay of accuracy and bias in partners' perceptions of each other's relational boredom, and how accurate and biased boredom perceptions were associated with relationship quality. Results revealed that, overall, partners overestimated-but accurately tracked—each other's relational boredom across the features that comprise relational boredom and across time. Additionally, when people accurately perceived their partner experiencing high levels of boredom, they reported lower relationship quality, but overestimation, underestimation, and accuracy at low levels were associated with high levels of relationship quality. Furthermore, when people accurately perceived their partner experiencing high levels of boredom, their partner also reported lower relationship quality, while only overestimation and accuracy at low levels were consistently associated with higher quality. These findings have important implications for how couples navigate boredom and maintain long-term relationships.
\end{abstract}

Keywords: Relational boredom, tracking accuracy, directional bias, relationship quality, response surface analysis 


\section{Are You Tired of “Us?” Accuracy and Bias in Couples' Perceptions of Relational}

\section{Boredom}

Romantic couples face several challenges when attempting to maintain satisfying, long-term relationships. One subtle but pervasive challenge couples are likely to encounter is relational boredom, the tendency for partners to feel "tired of" and unstimulated in their relationship (Harasymchuk \& Fehr, 2010, 2013). Past work suggests that when people experience boredom in their relationship they report a wide variety of negative emotions (e.g., lack of excitement, frustration) which can lead to declines in relationship quality (e.g. Reissman et al., 1993). In fact, one clinician concluded that "boredom is perhaps the most common denominator of all marital problems" (Venditti, 1980, p. 65). Thus, boredom is problematic for relationship success; however, what it means for the relationship to perceive that a partner is bored remains an open question. Are perceptions of a partner's relational boredom rooted in reality? What happens to the relationship if those perceptions are inaccurate? Or, to the perceiver's credit (but likely also to their chagrin), what happens if those perceptions are correct?

Guided by theoretical models of boredom, interdependence, and accuracy and bias in interpersonal perception, the present research had two goals. First, we investigated whether romantic partners accurately detect each other's levels of relational boredom, whether they over- or underestimate each other's boredom, and whether they draw on their own experiences of boredom when judging each other. Second, we examined whether partners' accurate and biased perceptions of relational boredom were associated with relationship satisfaction, commitment, and trust. We tested these ideas in two dyadic cross-sectional studies (Studies 1 and 2), and a 21-day dyadic daily experience study (Study 3). 


\section{Relational Boredom}

Boredom is a common experience. It is, interestingly, both a low- and higharousal state wherein people can feel simultaneously understimulated and restless (e.g., Danckert et al., 2018; Westgate, 2020). In their prototype analysis of relational boredom, Harasymchuk and Fehr $(2010,2013)$ found that when romantic partners describe what relational boredom feels like, they report negative emotions, including both low-arousal, low-pleasure emotions (e.g., feeling unexcited or tired) as well as high-arousal, low-pleasure emotions (e.g., feeling frustrated or anxious). These negative emotions stem primarily from a lack of novelty or stimulation within the relationship, or from external causes (e.g., work spillover, attractive alternatives). Unsurprisingly, then, boredom is frequently cited as a major reason for relationship discord and dissolution (Aron \& Aron, 1986; Reissman et al., 1993). Indeed, individuals experiencing relational boredom also tend to report lower investment and satisfaction in the relationship and a greater willingness to engage in infidelity (e.g., Gillen et al., 2012). As novelty-variety may even be an additional basic psychological need (Bagheri \& Milyavskaya, 2020), finding ways to remain engaged and stimulated in day-to-day lifeand especially in intimate relationships—has important consequences for well-being.

To date, researchers know much about experiences of relational boredom at the individual level. Intimate relationships, however, are inherently interdependent, meaning that the thoughts, feelings, and behaviors of one partner are informed by, and influence, the thoughts, feelings, and behaviors of the other partner (Kelley et al., 2003). As an example, imagine that Meredith and Derek are a romantic couple. Meredith's relational boredom is likely related to her own satisfaction and commitment, just as Derek's relational boredom is likely related to his own satisfaction and commitment. Interdependence theory posits that, because Meredith and Derek are part of a dyad, we 
must also consider how Meredith's relational boredom is related to Derek's satisfaction and commitment, and vice versa. In the present research, we test this mutual influence, especially in terms of how Meredith's perceptions of Derek's relational boredomcontrasted with Derek's actual experiences of boredom-are related to her own and Derek's relationship outcomes.

Like other relationship experiences, boredom conveys important information for partners (cf. Clore et al., 2001; Elpidorou, 2014), primarily that continuing the current course of action "as is" is neither fulfilling nor worthwhile (see Westgate, 2020). How romantic partners obtain and deal with this information, then, plays a key role in the future success of the relationship. However, partners experience opposing needs in relationships that may drive them to be accurate or inaccurate in their perceptions of each other's boredom. According to risk regulation theory (Murray et al., 2006, 2008), partners must balance the need for closeness, dependence, and intimacy with the need to maintain distance to protect the self from hurt and rejection. When regulating risk, individuals appraise their partner's feelings about the relationship and their likelihood of being rejected, actively gathering the information needed to respond in the future. Without making judgments of their partner's thoughts and feelings, individuals may not know whether to enact closeness-promoting behaviors that are "worth the risk," or to distance themselves from their partner to avoid being hurt. We argue that appraising a partner's relational boredom should be a regular part of navigating intimate relationships over time.

\section{Accuracy and Bias in Relationship Perceptions}

Partners' perceptions of each other tend to be accurate and rooted in reality; however, these perceptions often also contain some degree of bias (Fletcher \& Kerr, 2010; West \& Kenny, 2011). Collectively, extant literature points to three main forms of 
perceptual accuracy and bias. Tracking accuracy represents the extent to which perceivers can correctly detect the pattern of a partner's responses (e.g., across items of a scale, across time, etc.). Directional bias (also called mean-level bias) reflects the degree to which perceivers generally over- or underestimate their partner's responses. Lastly, assumed similarity (also called projection) represents the extent to which perceivers' judgments of their partner are predicted by their own beliefs.

Over the past two decades, there has been a swell of interest in understanding the dynamics and consequences of romantic partners' accurate and biased perceptions of each other, including perceptions of one's partner's ideal standards (Campbell et al., 2013), commitment (Overall \& Hammond, 2013), positive and negative emotions (Clark et al., 2017), regard during conflict discussions (Overall et al., 2012), approach and avoidance motives (LaBuda et al., 2019), sexual desire (Muise et al., 2016), and sexual advance behaviors (Dobson et al., 2018). This burgeoning literature points to the important interplay of accuracy and bias within intimate relationships, as well as the relationship consequences of accuracy and bias.

Partners are likely to accurately track the pattern of each other's relational boredom. Accurate appraisals of one's partner and relationship are an important component of effective risk regulation (Murray et al., 2006), as they balance the need to protect the self with the need to enhance and develop the relationship. Therefore, partners should be attuned to relationship-threatening feelings, such as each other's boredom. Returning to our hypothetical couple, Derek should be motivated to correctly detect Meredith's relational boredom because doing so will not only help him understand when Meredith's needs are not being met but may also protect him from continuing to invest in a relationship that Meredith previously found rewarding, but now believes is unfulfilling. Additionally, perceivers should be motivated to accurately 
judge their partner's boredom so that they can respond accordingly (e.g., by taking steps to maintain the relationship, or withdrawing from the unfulfilling relationship). Taken together, the literature strongly suggests that partners should judge relational boredom accurately.

Perceptions of relational boredom may also be biased in one direction. Generally, romantic partners who accurately perceive each other's thoughts and feelings enjoy happier relationships (Fletcher \& Kerr, 2010; Kenny \& Acitelli, 2001). Accurately perceiving a partner's thoughts and feelings in a relationship-threatening context, however, can undermine relationship satisfaction and stability (e.g., Sillars et al., 1984; Simpson et al., 1995). We propose that attempting to intuit a partner's levels of relational boredom is a potentially threatening endeavour. If Meredith believes that Derek has become bored with their relationship, these beliefs may lead her to worry that Derek will end their relationship, which may heighten her concerns about being hurt or rejected. In cases like this, where accurate knowledge of a partner's feelings may threaten the perceiver's self-esteem or their esteem of the relationship, both risk regulation theory (Murray et al., 2006) and the empathic accuracy model (Ickes \& Simpson, 1997) suggest that people are motivated to be inaccurate. Guided by this idea, underestimating a partner's relational boredom may be a self-protective reaction to the potential relationship threat of knowing that a partner is bored.

\section{The Present Research}

Although a good amount is known about individuals' experiences of boredom within their relationships, no research has examined whether accurate and biased perceptions of boredom play a role in relationship quality. We address this gap in three dyadic studies. In Studies 1-2, we tested partners' cross-sectional experiences of tracking accuracy, directional bias, and assumed similarity, and the associations of 
accuracy and bias with relationship quality (satisfaction, commitment, and trust). In Study 3, we extended our first two studies by investigating these effects longitudinally in partners' day-to-day lives. Study 3 also explored the possible motivational function of accurate and biased perceptions of relational boredom, testing whether accurate knowledge of a partner's boredom predicted subsequent behaviors aimed at coping with that boredom (e.g., endeavouring to introduce more novelty into the relationship). Lastly, in Study 3 we explored whether partners' boredom coping behaviors served as a cue for actual boredom, and if perceivers used that cue to inform their judgments.

\section{Study 1}

Our first goal in Study 1 was to investigate the interplay of accuracy and bias in partners' perceptions of relational boredom. We predicted that partners would demonstrate tracking accuracy in their judgments of each other's boredom, a hypothesis consistent with prior research (Fletcher \& Kerr, 2010). Guided by studies showing that people tend to project their own relationship experiences onto their perceptions of their partner (e.g., Kenny \& Acitelli, 2001), we also expected that partners would assume similarity when judging each other's boredom. Lastly, we anticipated that perceivers would underestimate their partner's boredom, erring in a manner that protects the self from relationship threat (Murray et al., 2006, 2008).

Our second goal was to examine how accurate and biased perceptions of relational boredom would predict perceivers' and partners' satisfaction, commitment, and trust. In line with the concept of motivated inaccuracy (Ickes \& Simpson, 1997), we anticipated that underestimation of boredom, as well as tracking accuracy, would be associated with better relationship outcomes for perceivers. We explored the possibility that the link between directional bias and relationship outcomes would differ for perceivers' partners, because underestimation may mean that perceivers have "missed 
the mark" with how their partner truly feels about the relationship. In contrast, overestimation of boredom may indicate to perceivers that they should enact relationship maintenance behaviors, which could promote better relationship outcomes for partners. However, given that it is currently unclear in the literature how one form of directional bias or the other should be linked to relationship quality for perceivers and partners, we made no firm a priori predictions and kept these analyses exploratory in Study 1. Our a priori hypotheses, materials, analytic plan, data, output, and syntax appear at https://osf.io/vj87q/.

\section{Method}

\section{Participants}

The original sample was 84 couples, but four same-sex couples were removed from analyses as there were not enough for comparison to opposite-sex couples, and to be consistent with the other studies reported in this paper. The final sample comprised 80 heterosexual romantic couples recruited from the London, Ontario community. Participants were 18-68 years of age $\left(M_{\text {years }}=23.64, S D_{\text {years }}=8.21\right)$ and were in relationships lasting 1 month to 38 years $\left(M_{\text {years }}=2.83, S D_{\text {years }}=5.33\right)$. Approximately $83 \%$ of participants were casually or exclusively dating their current partner, and $17 \%$ were common-law, engaged, or married. A minority of couples (36\%) were cohabiting.

\section{Measures and Procedure}

Data were taken from a larger cross-sectional study examining psychological experiences in romantic couples (see https://osf.io/ih2s5). ${ }^{1}$ Couples arrived at the lab together, where they separately and privately completed a battery of questionnaires that included the variables of interest to the present research. The study lasted

\footnotetext{
${ }^{1}$ Unrelated data from this study were presented in Muise et al. (2016).
} 
approximately 90 minutes in full and was completed in a single session. After completing the study questionnaires, partners were debriefed and received CAD- $\$ 15.00$ each as compensation for their participation.

\section{Relational Boredom}

Participants completed two versions of the Relational Boredom Scale (RBS; Harasymchuk \& Fehr, 2012), a 15-item measure rated on a 7-point scale $(1=$ not at all true, 7 = completely true) wherein they indicated how well a series of brief descriptors characterized their relationship (e.g., "dull”; "full of surprises," reverse-scored). In one version, participants reported their own levels of relational boredom $(M=2.22, S D=.88$, $\alpha=.89$ ), and in the second version they reported their perceptions of their partner's levels of relational boredom $(M=2.28, S D=.88, \alpha=.89)$. Each partner thus created a relational boredom profile for themselves and their beliefs about their partner.

\section{Relationship Quality}

Participants reported their satisfaction using the Relationship Assessment Scale (RAS; Hendrick, 1988), a 7-item measure rated on a 5-point scale (1 = not at all/extremely poor, 5 = a great deal/extremely good) that assesses how happy individuals are in their current relationship (e.g., "How good is your relationship compared to most?"). Participants reported their commitment using the commitment subscale of the Investment Model Scale (IMS; Rusbult et al., 1998), a 7-item measure rated on a 9-point scale $(0=$ do not agree at all, $8=$ agree completely $)$ that assesses how dedicated individuals are to their current relationship (e.g., "I want our relationship to last for a very long time”). Participants reported their trust using Rempel et al.'s (1985) 17-item measure rated on a 7 -point scale $(1=$ strongly disagree, $7=$ strongly agree $)$ that assesses individuals' beliefs about their partner's dependability and honesty (e.g., "My partner has proven to be trustworthy and I am willing to let him/her engage in 
activities which other partners find too threatening"). Scores were calculated by averaging responses across items, with higher scores indicating greater satisfaction $(\alpha=$ .86), commitment ( $\alpha=.89)$, and trust $(\alpha=.85)$, respectively.

\section{Results}

We used two distinct, but complementary, statistical approaches to guide our hypothesis-testing, described in detail below.

\section{Identifying the Patterns of Accuracy and Bias in Relational Boredom Perceptions}

The analyses testing our first research question were guided by West and Kenny's (2011) Truth and Bias (T\&B) Model of Judgment. Our data have a nested structure, with perceivers' and partners' multiple ratings of relational boredom across the 15 RBS items (Level 1) nested within dyad (Level 2). In accordance with the T\&B Model, the perceiver's judgments of their partner's boredom-the outcome-were centered on the partner's actual boredom ratings by subtracting the grand mean of all partners' boredom ratings (i.e., mean across dyads) from the perceivers' judgments for each item. Using this method of centering, the intercept represents the difference between the mean of the partner's actual boredom ratings and the mean of the perceiver's judgments of those ratings. The average of this coefficient across perceivers tests whether their judgments differed from the partners' actual ratings across the boredom items, and in what direction (i.e., directional bias). A positive average intercept indicates that perceivers generally overestimate partners' boredom, whereas a negative average intercept indicates that perceivers generally underestimate partners' boredom. The effect (slope) of the partner's actual boredom ratings on the perceiver's judgments of those ratings reflects tracking accuracy, and the effect (slope) of the perceiver's own boredom ratings on their judgments of their partner's boredom reflects assumed 
similarity (i.e., projection). A positive slope indicates higher tracking accuracy or assumed similarity, respectively.

As seen in the Study 1 column of Table 1, counter to expectations, perceivers marginally overestimated the degree to which their partner was bored with their relationship. In line with predictions, however, perceivers also demonstrated tracking accuracy and assumed similarity when making judgments of their partner's boredom. 


\section{Table 1}

Directional Bias, Tracking Accuracy, and Assumed Similarity in Perceptions of the Partner's Boredom

\begin{tabular}{|c|c|c|c|c|c|c|c|c|c|}
\hline \multirow[b]{2}{*}{ Perception Parameter } & \multicolumn{3}{|c|}{ Study 1} & \multicolumn{3}{|c|}{ Study 2} & \multicolumn{3}{|c|}{ Study 3} \\
\hline & $b(S E)$ & $\mathrm{CI}_{95 \%}$ & $R^{2}$ & $b(S E)$ & $\mathrm{CI}_{95 \%}$ & $R^{2}$ & $b(S E)$ & $\mathrm{CI}_{95 \%}$ & $R^{2}$ \\
\hline Directional Bias & $.07(.04) \dagger$ & {$[-.01, .14]$} & .05 & $.18(.05)^{* * *}$ & {$[.08, .28]$} & .11 & $.11(.03)^{* * *}$ & {$[.05, .18]$} & .12 \\
\hline Tracking Accuracy & $.11(.02)^{* * *}$ & {$[.07, .15]$} & .35 & $.32(.02)^{* * *}$ & {$[.28, .37]$} & .65 & $.14(.03)^{* * *}$ & {$[.08, .21]$} & .15 \\
\hline Assumed Similarity & $.63(.03)^{* * *}$ & {$[.58, .69]$} & .86 & $.46(.03)^{* * *}$ & {$[.41, .52]$} & .72 & $.75(.04)^{* * *}$ & {$[.67, .83]$} & .79 \\
\hline
\end{tabular}

Note. $N_{\text {Study } 1}=80$ heterosexual couples; $N_{\text {Study } 2}=136$ heterosexual couples; $N_{\text {Study } 3}=115$ heterosexual couples. We report unstandardized coefficients, with standard errors in parentheses. Approximate effect sizes were computed using the formula $R^{2}=\frac{\left(\frac{\text { Numerator } d f}{\text { Denominator } f f}\right) \times F}{1+\left(\left(\frac{\text { Numeratordf }}{\text { Denominator } d f}\right) \times F\right)}($ see Edwards et al., 2008 ; Page-Gould, 2016). Degrees of freedom ranged from 62.81-80.28 (Study 1), 106.49-120.13 (Study 2), and 89.74-102.02 (Study 3).

$\dagger p<.10,{ }^{* * *} p \leq .001$ 


\section{Testing the Consequences of Accuracy and Bias in Boredom Perceptions}

To test our second research question, we used multilevel polynomial regression with response surface analysis (RSA; Edwards, 2002) following guidelines from previous research regarding the application of RSA to social psychological research (Barranti et al., 2017; Shanock et al., 2010). These analyses allowed us to test how the degree of agreement between partners (accuracy) and how the direction of disagreement between partners (bias) were associated with relationship satisfaction, commitment, and trust. In accordance with Shanock et al.'s (2010) specifications, we centered the scores for perceivers' judgments of their partner's boredom and the partner's actual reported boredom on the midpoint of the scale (i.e., 4). We then created squared versions of these variables, as well as the interaction between perceived partner boredom and actual partner boredom, and entered all five variables as predictors in our dyadic multilevel models. We ran separate models for each relationship quality outcome. ${ }^{2}$

The output obtained from the polynomial regression models is not interpreted directly; instead, the output is used to examine the significance of four surface test values (a1, a2, a3, and a4), which we tested by entering the five coefficients from the polynomial regression models and their standard errors into a spreadsheet provided by Shanock et al. (2010). In RSA, the line of congruence represents the level of relationship satisfaction, commitment, and trust when perceivers' and partners' ratings of the 15

\footnotetext{
2 Originally, we created and tested a composite relationship quality score by averaging the standardized scores for relationship satisfaction, commitment, and trust. However, we later had concerns about the conceptual validity of this composite score and opted instead to run separate models for each relationship quality component. One result was inconsistent across the different operationalizations of the outcome variables: For perceivers, underestimation (vs. overestimation) of the partner's boredom was linked with higher composite relationship quality, but this effect was consistently nonsignificant when satisfaction, commitment, and trust were examined separately. Thus, in the main text of this paper we present the separate analyses for our three outcomes. We note, however, that this decision was made after hypotheses for Studies 2-3 were preregistered.
} 
RBS items are essentially identical. The slope of the line of congruence is captured by $\mathbf{a}_{1}$, which reveals whether matches at high values of the predictors yield different outcomes than matches at low values. A positive a1 indicates that when perceivers' judgments of the partner's boredom and partners' actual boredom ratings are in agreement and increase, levels of the outcome are higher, whereas a negative $\mathrm{a}_{1}$ indicates that when perceivers' judgments of the partner's boredom and partners' actual boredom ratings are in agreement and increase, levels of the outcome are lower. The curvature along the line of congruence is captured by $\mathbf{a}$, which reveals whether matches at extreme values of the predictors yield different outcomes than matches at less extreme values. A significant positive $\mathrm{a}_{2}$ indicates that matches at extreme values predict higher levels of the outcome compared to matches at less extreme values.

The line perpendicular to the line of congruence is the line of incongruence, which represents the level of relationship quality when perceivers' and partners' ratings of the 15 RBS items mismatch. The slope of the line of incongruence is captured by $\mathbf{a}_{3}$, which reveals whether one type of mismatch between the predictors (e.g., overestimation vs. underestimation) yields different outcomes than the other type of mismatch. A positive a3 indicates that when perceivers overestimate (vs. underestimate) their partner's relational boredom, levels of the outcome are higher, whereas a negative a3 indicates that when perceivers underestimate (vs. overestimate) their partner's boredom, levels of the outcome are higher. The curvature along the line of incongruence is captured by a4, which reveals whether matches at predictor values yield different outcomes than mismatches. A significant positive $\mathrm{a}_{4}$ indicates that mismatches (inaccuracy) are associated with higher levels of the outcome than matches (accuracy).

The above description of surface test values indicates how each value would be interpreted if it occurred in isolation (Barranti et al., 2017), and served as the basis for 
our original hypotheses. However, recent concerns raised by statisticians emphasize the limitations of interpreting surface test values independently (e.g., Humberg et al., 2019). Although we recognize that the four surface test values rarely occur in isolation and must be interpreted together, to the best of our knowledge there are currently no firm guidelines on how to do this in the context of accuracy and bias in perceivers' judgments of their partners. Thus, at present it appears to be up to the researcher to consider the size and validity of RSA effects based on theoretical consistency and prior empirical studies. In sum, our primary focus originally (at the time of preregistration) was to examine how accuracy (best represented by $\mathrm{a}_{1}$ and $\mathrm{a}_{4}$ ) and bias (best represented by $\mathrm{a}_{3}$ ) predict relationship satisfaction, commitment, and trust, but we now report all surface test values and interpret their overall pattern, as advised by Humberg et al. (2019). ${ }^{3}$ The results from the RSA analyses may be viewed in Table 2 and Figures 1A (perceiver outcomes) and 1B (partner outcomes). In all studies, RSA graphs were plotted using the R package RSA (Schönbrodt \& Humberg, 2018). When perceivers' judgments of their partner's relational boredom and the partner's actual boredom were high, both perceivers and partners experienced lower relationship satisfaction, commitment, and trust. Perceivers' and partners' relationship outcomes were protected, however, if perceptions of the partner's boredom, the partner's actual boredom, or both, were low. We also found interesting differences across perceivers and partners as to whether mismatches in the predictors were linked to levels of their relationship outcomes. Perceivers' relationship outcomes did not vary based on whether they overor underestimated their partner's relational boredom (see Figure 1A). However,

\footnotetext{
3 When Studies 1-2 were originally preregistered, some key RSA interpretation papers (e.g., Barranti et al., 2017; Humberg et al., 2019) were not yet published. Thus, the interpretation of results in the main text-which reflects the more robust manner of understanding RSA when answering questions regarding accuracy and bias-may not correspond completely with the wording of hypotheses from our preregistration documents.
} 
partners enjoyed better relationship outcomes when perceivers overestimated (vs. underestimated) how bored they were with the relationship.

\section{Table 2}

Study 1: Associations of Accurate and Biased Perceptions of the Partner's Boredom with Relationship Outcomes

\begin{tabular}{ccccc}
\hline \multirow{2}{*}{ Relationship Outcome } & \multicolumn{2}{c}{ Line of Congruence } & \multicolumn{2}{c}{ Line of Incongruence } \\
\cline { 2 - 5 } & Slope $\mathrm{a}_{1}$ & Curvature $\mathrm{a}_{2}$ & Slope $\mathrm{a}_{3}$ & Curvature $\mathrm{a}_{4}$ \\
\hline Perceiver Satisfaction & $-.18(.03)^{* * *}$ & $-.04(.01)^{* * *}$ & $-.03(.02)$ & $.03(.01)^{*}$ \\
Perceiver Commitment & $-.28(.08)^{* * *}$ & $-.07(.03)^{*}$ & $-.07(.04)$ & $.10(.04)^{*}$ \\
Perceiver Trust & $-.26(.04)^{* * *}$ & $-.05(.01)^{* * *}$ & $-.01(.02)$ & $.08(.02)^{* * *}$ \\
Partner Satisfaction & $-.23(.04)^{* * *}$ & $-.05(.01)^{* * *}$ & $.07(.02)^{* * *}$ & $.06(.01)^{* * *}$ \\
Partner Commitment & $-.33(.08)^{* * *}$ & $-.07(.03)^{*}$ & $.13(.05)^{* *}$ & $.10(.05)^{*}$ \\
Partner Trust & $-.26(.04)^{* * *}$ & $-.06(.01)^{* * *}$ & $.05(.02)^{* *}$ & $.07(.02)^{* * *}$ \\
\hline
\end{tabular}

Note. We report unstandardized coefficients, with standard errors in parentheses.

${ }^{*} p<.05,{ }^{* *} p<.01,{ }^{* * *} p \leq .001$ 


\section{Figure 1A}

Study 1: Response Surface Plots Displaying the Associations of Accurate and Biased Perceptions of the Partner's Boredom with Perceiver Relationship Outcomes
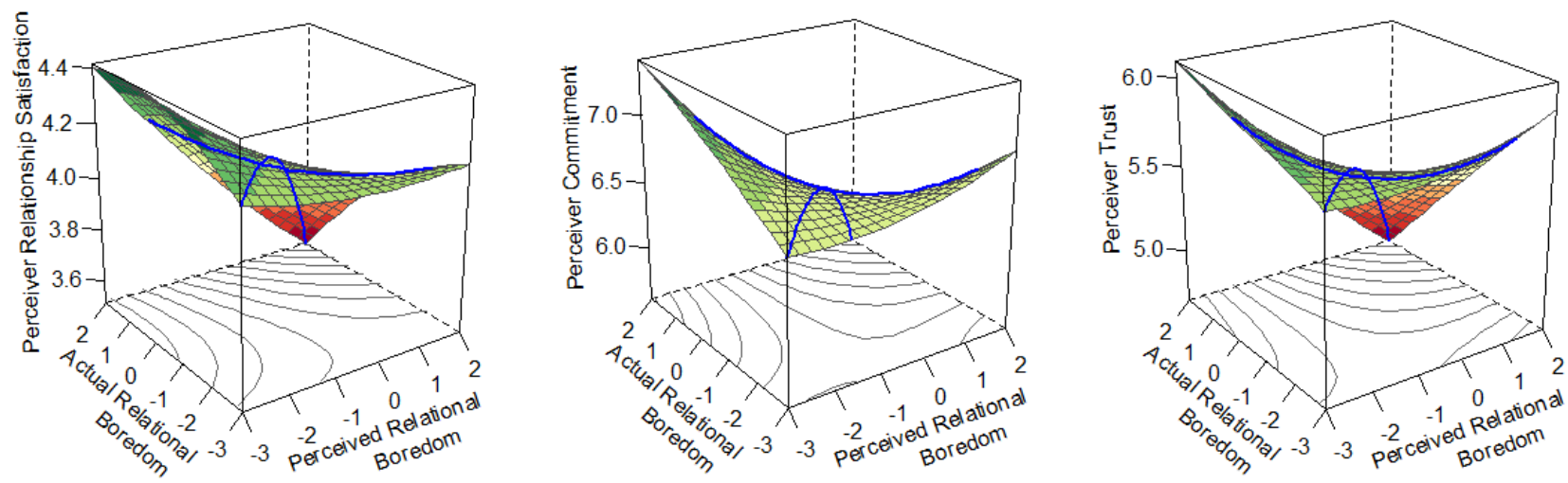

Note. The line of congruence runs from the front corner to the back corner, and the line of incongruence runs from the left corner to the right corner.

\section{Figure 1B}

Study 1: Response Surface Plots Displaying the Associations of Accurate and Biased Perceptions of the Partner's Boredom with Partner Relationship Outcomes
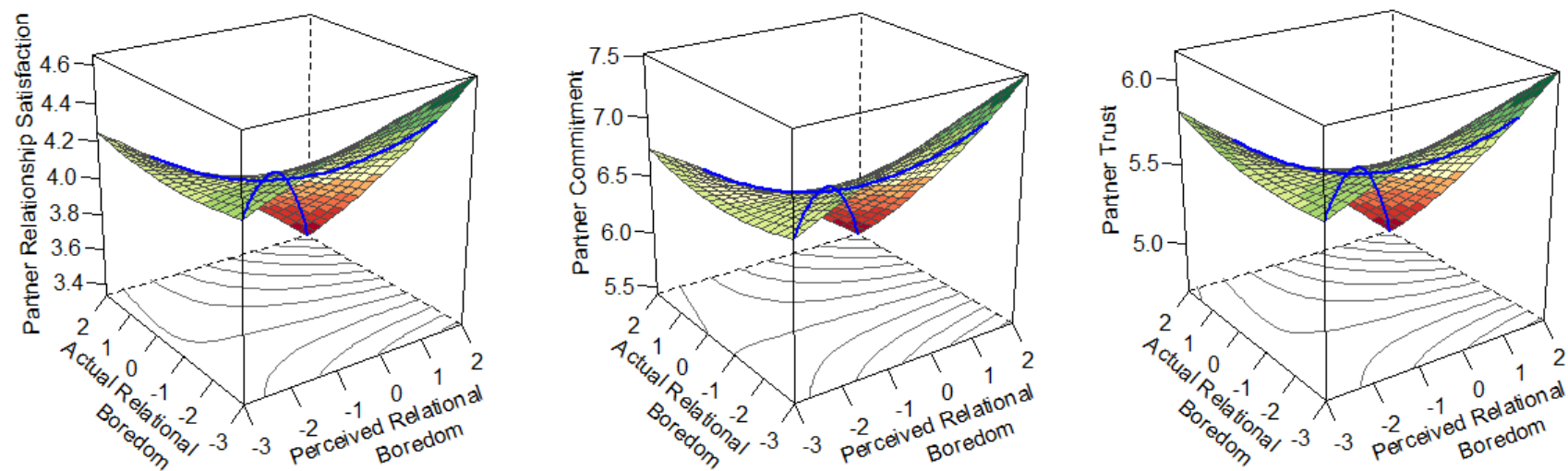

Note. The line of congruence runs from the front corner to the back corner, and the line of incongruence runs from the left corner to the right corner. 


\section{Study 2}

Study 2 sought to replicate Study 1 in a new sample of romantic couples. Guided by our findings in Study 1, in Study 2 we predicted that perceivers would demonstrate tracking accuracy and assumed similarity in their judgments of their partner's relational boredom. Consistent with Study 1 and notion that overestimating one's partner's boredom may protect the relationship by prioritizing the partner rather than the self (cf. Murray et al., 2008), we also hypothesized that perceivers would overestimate their partner's boredom. Additionally, following from Study 1 we anticipated that accuracy and bias would be associated with relationship satisfaction and commitment (trust was not assessed in Study 2 and thus could not be tested). We expected that accuracy (vs. inaccuracy) would be linked to worse relationship outcomes for both perceivers and partners. In terms of bias, we anticipated replicating the different outcomes for perceivers compared to partners, such that underestimation would be linked to better outcomes for perceivers, whereas overestimation would be linked to better outcomes for partners. ${ }^{4}$ Our a priori hypotheses, materials, analytic plan, data, output, and syntax appear at https://osf.io/krdbw/.

\section{Method}

\section{Participants}

This was a two-part study conducted by Qualtrics Panel. For Part 1 of the study, 6,108 couples began the survey session. Couples were then automatically screened out

\footnotetext{
${ }^{4}$ In our original preregistration, two additional hypotheses were included relating to relationship security and boredom coping behaviors. However, we opted not to test these hypotheses in Study 2 for two reasons. First, given the reinterpretation of the RSA analyses from Study 1 to consider all surface test values in tandem and the fact that the effect of underestimation on perceiver relationship outcomes was no longer significantly different from overestimation when separated into individual components (satisfaction, commitment, and trust), this meant that the additional models we planned to run were unfounded. Second, the boredom coping measure only assessed experiences in the last day, but all other measures assessed overall relationship experiences, which undermined its inclusion in analyses.
} 
and removed by Qualtrics Panel during the survey (i.e., their survey session was automatically ended and they did not see any additional questions) if one or both partners did not consent to participate $(N=1,269)$; were under 18 years of age $(N=$ 28); were not fluent in English $(N=66)$; were not currently involved in a romantic relationship $(N=1,361)$; had not been together for at least four months $(N=60)$; or were not heterosexual $(N=697)$. Couples were also automatically removed by Qualtrics Panel for failing attention checks $(N=2,099)$, because they admitted to discussing their survey responses with their partner during the study $(N=181)$, or because they indicated they were unwilling to participate in Part 2 of the study $(N=211)$. Thus, in total, 5,972 couples were excluded from the study.

The final sample comprised 136 heterosexual romantic couples recruited by Qualtrics Panel. Participants were 20-84 years of age $\left(M_{\text {years }}=48.87, S D_{\text {years }}=14.58\right)$ and were in relationships lasting 7 months to 55 years $\left(M_{\text {years }}=20.66, S D_{\text {years }}=14.57\right)$. Approximately $6 \%$ of participants were casually or exclusively dating their current partner, and 94\% were common-law, engaged, or married. Most couples (96\%) were cohabiting.

\section{Measures and Procedure}

The data were collected as part of a larger study on romantic and sexual ideals. Couples accessed the study online and separately and privately completed a battery of questionnaires that included the variables of interest to the present research across two study sessions that were two weeks apart. The study lasted approximately 20 minutes per survey session. After completing the study questionnaires, partners were debriefed and received prorated compensation for their participation based on how many questionnaires they answered (up to US- $\$ 1.08$ for Part 1 of the study and up to US- $\$ 1.40$ for Part 2). For the present research, we use only Part 1 data. 


\section{Relational Boredom}

Participants completed the same two versions of the RBS (Harasymchuk \& Fehr, 2012) as in Study 1 (actual boredom: $\alpha=.95, M=2.78, S D=1.39$; perceived boredom: $\alpha$ $=.96, M=2.92, S D=1.44)$.

\section{Relationship Outcomes}

Participants reported their satisfaction and commitment using a subset of items from the corresponding subscales of the IMS (Rusbult et al., 1998). Satisfaction was measured with 3 items (e.g., "I feel satisfied with our relationship") and commitment was measured with 4 items (e.g., "I am committed to maintaining my relationship with my partner"). All items were rated on a 9-point scale (1 = do not agree at all, 9 = agree completely). Scores were calculated by averaging responses across items, with higher scores indicating greater satisfaction $(\alpha=.94)$, and commitment $(\alpha=$ .96), respectively.

\section{Results}

The data analytic strategy in Study 2 was identical to Study 1.

\section{Patterns of Accuracy and Bias in Relational Boredom Perceptions}

As seen in the Study 2 column of Table 1, consistent with Study 1, perceivers significantly overestimated the degree to which their partner was bored with their relationship, demonstrated tracking accuracy, and assumed similarity between their own and their partner's boredom.

\section{Testing the Consequences of Accuracy and Bias in Boredom Perceptions}

The results from the RSA analyses may be viewed in Table 3 and Figures 2A (perceiver outcomes) and 2B (partner outcomes). Consistent with Study 1, when perceivers' judgments of their partner's relational boredom and the partner's actual boredom were high, both perceivers and partners experienced lower relationship 
satisfaction and commitment. Also consistent with Study 1, accuracy at low levels of actual relational boredom was not associated with lower levels of relationship quality (see Figures 2A and 2B). Perceivers' and partners' relationship outcomes were protected, however, if perceptions of the partner's boredom, the partner's actual boredom, or both, were low (except for partners' relationship satisfaction, which was not preserved if the perceiver underestimated). Additionally, partners in particular enjoyed better relationship quality when perceivers overestimated (vs.

underestimated) how bored they were with the relationship. In sum, Study 2 replicated all three accuracy effects and 12 of 16 individual surface values (including both overall patterns of effects).

\section{Table 3}

Study 2: Associations of Accurate and Biased Perceptions of the Partner's Boredom with Relationship Outcomes

\begin{tabular}{|c|c|c|c|c|}
\hline \multirow[b]{2}{*}{ Relationship Outcome } & \multicolumn{2}{|c|}{ Line of Congruence } & \multicolumn{2}{|c|}{ Line of Incongruence } \\
\hline & Slope $a_{1}$ & Curvature $\mathrm{a}_{2}$ & Slope $a_{3}$ & Curvature $\mathrm{a}_{4}$ \\
\hline Perceiver Satisfaction & $-.44(.07)^{* * *}$ & $-.06(.03)^{*}$ & $-.10(.07)$ & $.13(.06)^{*}$ \\
\hline Perceiver Commitment & $-.14(.04)^{* * *}$ & $-.02(.02)$ & $.01(.05)$ & $.01(.05)$ \\
\hline Partner Satisfaction & $-.49(.06)^{* * *}$ & $-.06(.02)^{*}$ & $.26(.06)^{* * *}$ & $.09(.06) \dagger$ \\
\hline Partner Commitment & $-.29(.04)^{* * *}$ & $-.003(.01)$ & $.12(.06)^{*}$ & $.07(.02)^{* * *}$ \\
\hline
\end{tabular}

Note. We report unstandardized coefficients, with standard errors in parentheses.

$\dagger p<.10,{ }^{*} p<.05,{ }^{* * *} p<.001$ 


\section{Figure 2A}

Study 2: Response Surface Plots Displaying the Associations of Accurate and Biased Perceptions of the Partner's Boredom with Perceiver Relationship Outcomes
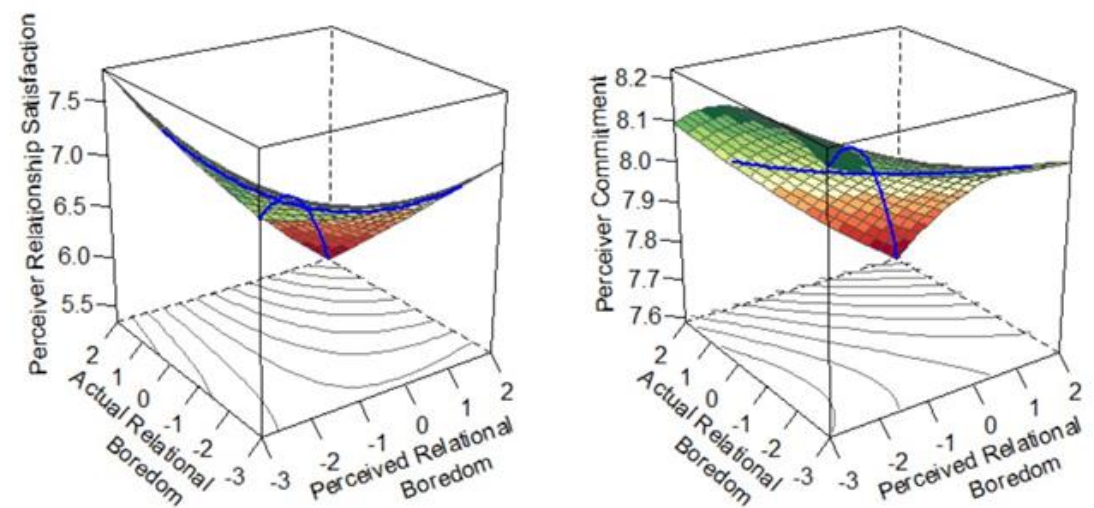

Note. The line of congruence runs from the front corner to the back corner, and the line of incongruence runs from the left corner to the right corner.

\section{Figure 2B}

Study 2: Response Surface Plots Displaying the Associations of Accurate and Biased Perceptions of the Partner's Boredom with Partner Relationship Outcomes
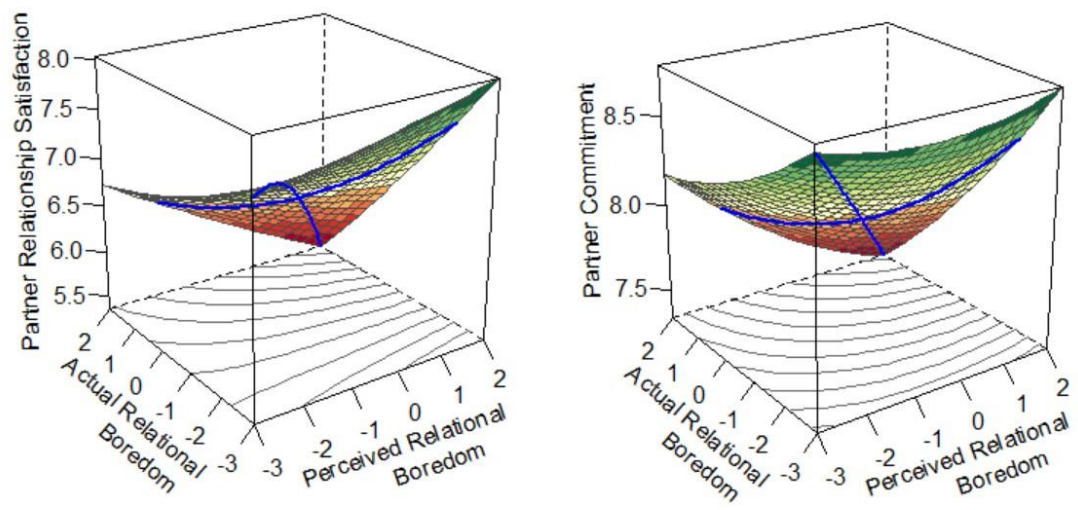

Note. The line of congruence runs from the front corner to the back corner, and the line of incongruence runs from the left corner to the right corner. 


\section{Study 3}

Past research suggests that relational boredom fluctuates over time (Aron \& Aron, 1986; Harasymchuk \& Fehr, 2010), and such fluctuations may meaningfully impact partners' ability to accurately perceive one another's relational boredom. The purpose of Study 3 was to determine whether romantic partners demonstrate accuracy and bias in their perceptions of each other's boredom over time, and whether changes in relationship quality can be predicted by changes in accuracy and bias. Guided by our findings in Studies 1-2, in Study 3 we predicted that perceivers would overestimate their partner's boredom and assume similarity between their own and their partner's experiences. Additionally, we predicted that perceivers would display tracking accuracy across time, rather than across the features that comprise relational boredom examined in Studies 1-2. Furthermore, we expected that accuracy and bias would be associated with relationship satisfaction, commitment, and trust over time, such that perceivers' and partners' relationship quality would be lower when both perceptions of and actual boredom were high. If perceptions of the partner's boredom, the partner's actual boredom, or both were low, however, we anticipated that this would be associated with higher levels of relationship quality, consistent with our prior studies. Lastly, we anticipated replicating the effects of bias on perceiver and partner outcomes, such that overestimation would be linked to better outcomes for partners.

In Study 3, we also sought to extend our previous findings by exploring the potential signalling function of relational boredom for perceivers and their partners. Specifically, we explored whether perceivers' biased judgments of relational boredom were associated with them engaging in active, relationship-focused coping behaviors aimed at maintenance, such as attempting to increase novelty or communication with their partner. We also explored the reverse side of this idea; that is, whether a decrease 
in partners' boredom coping behaviors acts as a cue for perceivers that not all is well within the relationship. Boredom coping behaviors likely have a reciprocal relation with boredom perceptions, as failing to engage in those behaviors is likely a cue that the partner may be bored, and perceiving a partner to be bored should signal a need for coping behaviors. Taking into account the potentially dynamic nature of boredom over time, we tested these exploratory analyses in same-day models that investigated the signalling function of boredom on a given day, while accounting for the previous day's coping behaviours (i.e. potential cues). Our a priori hypotheses, materials, analytic plan, data, and syntax appear at https://osf.io/3tgp5/.

\section{Method}

\section{Participants}

The original sample was 130 cohabiting couples, but 15 couples were excluded from analyses because one or both partners did not consent to participate in the study $(N=5)$; were not heterosexual or monogamous $(N=5)$; were not fluent in English $(N=$ 1); or because they did not complete at least three diary surveys $(N=4)$. The final sample comprised 115 heterosexual romantic couples recruited via advertisements posted on Kijiji, Facebook, and a participant email list, in addition to flyers posted around the local community. Participants were $19-64$ years of age $\left(M_{\text {years }}=30.78, S D_{\text {years }}\right.$ $=8.99)$ and were in relationships lasting 5 months to 26 years $\left(M_{\text {years }}=6.83, S D_{\text {years }}=\right.$ 5.87). Approximately $42 \%$ of participants were casually or exclusively dating their current partner, and 58\% were common-law, engaged, or married.

\section{Measures and Procedure}

The data for this study were collected as part of a larger study on daily relationship and sexual experiences (see https://osf.io/42npz/). Couples accessed the three-phase study online. Phase 1 was a 30-minute background survey, Phase 2 was a 
daily experience period wherein partners completed 10-minute surveys each day for 21 consecutive days, and Phase 3 was a 30-minute follow-up survey that occurred two days following the end of Phase 2. During Phase 2, general relationship questions (including the relational boredom measures) were included on odd numbered days, and sexuality-based measures were included on even numbered days. Partners were asked to complete questionnaires separately and privately. We used shortened versions of the focal study measures in Phase 2 to reduce fatigue, increase efficiency, and minimize participant attrition (Bolger et al., 2003). After completing all three phases of the study, partners were debriefed and received prorated compensation for their participation based on how much of the study they completed (up to CAD- $\$ 35.00$ per person). For the present research, we use measures and data only from Phase $2 .{ }^{5}$

\section{Daily Relational Boredom}

On odd-numbered days during Phase 2, participants completed the same two versions of the RBS (Harasymchuk \& Fehr, 2012) as in Studies 1-2 (actual boredom: $R c$ $=.84, M=2.38, S D=1.09$; perceived boredom: $R c=.85, M=2.49, S D=1.18)$.

\section{Daily Relationship Outcomes}

Participants reported their daily satisfaction using 4 items from the RAS (Hendrick, 1988; e.g., "How satisfied are you with your relationship?”) rated on a 5point scale (1 = not at all/extremely poor, 5 = a great deal/extremely good $)$. Participants reported their daily commitment using 3 items from the corresponding subscale of the IMS (Rusbult et al., 1998; e.g., "I feel very attached to our relationship") rated on a 9point scale $(0=$ do not agree at all, $8=$ agree completely $)$. Participants reported their

\footnotetext{
${ }^{5}$ Our original preregistration included using responses from Phase 1 and 3 questionnaires and standardizing them to be comparable to the shortened daily questionnaires. However, after further consideration and consultation with statistics experts regarding the efficacy of this choice, we altered our plan and opted to test only the Phase 2 responses in our analyses.
} 
daily trust using 3 items (e.g., "My partner is dependable") rated on a 7-point scale (1 = strongly disagree, 7 = strongly agree). Scores were calculated by averaging responses across items, with higher scores indicating greater satisfaction $(R c=.80)$, commitment $(R c=.90)$, and trust $(R c=.86)$, respectively.

\section{Daily Boredom Coping}

Participants completed a checklist wherein they indicated whether they had engaged in any of 7 common boredom coping behaviors with their partner each day (e.g., "Tried new things with your partner"; "Watched a movie with your partner") adapted from Harasymchuk and Fehr (2010).

\section{Results}

The data analytic strategy in Study 3 was comparable to Studies 1-2. In Study 3, perceivers' and partners' ratings of their own boredom and their perceptions of each other's boredom across the 21 diary days (mean aggregate per day; Level 1) were nested within dyad (Level 2).

\section{Patterns of Accuracy and Bias in Relational Boredom Perceptions}

As seen in the Study 3 column of Table 1, consistent with Studies 1-2, perceivers significantly overestimated the degree to which their partner was bored with their relationship and assumed similarity when making judgments of their partner's boredom. Additionally, perceivers demonstrated tracking accuracy, indicating they accurately tracked fluctuations in their partner's boredom over the course of 21 days.

\section{Testing the Consequences of Accuracy and Bias in Boredom Perceptions}

The results from the RSA analyses may be viewed in Table 4 and Figures 3A (perceiver outcomes) and 3B (partner outcomes). Consistent with Studies 1-2, when perceivers' judgments of their partner's relational boredom and the partner's actual boredom were high, both perceivers and partners experienced lower relationship 
satisfaction, commitment, and trust. However, perceivers' relationship outcomes were protected if perceptions of the partner's boredom, the partner's actual boredom, or both, were low. Partners' relationship outcomes were protected only if their actual boredom levels, or both perceptions and actual levels, were low, a finding different from Study 1 and partially consistent with Study 2. Thus, partners again enjoyed better relationship outcomes when perceivers overestimated (vs. underestimated) how bored they were with the relationship. In sum, Study 3 replicated all three accuracy effects from Studies 1-2, 19 of 24 individual surface values from Study 1, and 11 of 16 surface values from Study 2 (including overall patterns of effects).

Table 4

Study 3: Associations of Accurate and Biased Perceptions of the Partner's Boredom with Relationship Outcomes

\begin{tabular}{|c|c|c|c|c|}
\hline \multirow[b]{2}{*}{ Relationship Outcome } & \multicolumn{2}{|c|}{ Line of Congruence } & \multicolumn{2}{|c|}{ Line of Incongruence } \\
\hline & Slope $\mathrm{a}_{1}$ & Curvature $\mathrm{a}_{2}$ & Slope $a_{3}$ & Curvature $a_{4}$ \\
\hline Perceiver Satisfaction & $-.92(.07)^{* * *}$ & $-.17(.03)^{* * *}$ & $-.20(.08)^{*}$ & $.08(.04)^{*}$ \\
\hline Perceiver Commitment & $-1.15(.09)^{* * *}$ & $-.22(.04)^{* * *}$ & $-.22(.15)$ & $.08(.06)$ \\
\hline Perceiver Trust & $-.73(.06)^{* * *}$ & $-.07(.02)^{* *}$ & $-.09(.10)$ & $.15(.04)^{* * *}$ \\
\hline Partner Satisfaction & $-.74(.03)^{* * *}$ & $-.10(.01)^{* * *}$ & $.38(.05)^{* * *}$ & $-.05(.02)^{* *}$ \\
\hline Partner Commitment & $-.86(.05)^{* * *}$ & $-.16(.02)^{* * *}$ & $.52(.08)^{* * *}$ & $-.03(.04)$ \\
\hline Partner Trust & $-.93(.08)^{* * *}$ & $-.15(.03)^{* * *}$ & $.35(.12)^{* *}$ & $-.10(.05)^{*}$ \\
\hline
\end{tabular}

Note. $N_{\text {study }}$ = 115 heterosexual couples. We report unstandardized coefficients, with standard errors in parentheses.

${ }^{*} p<.05,{ }^{* *} p<.01,{ }^{* * *} p<.001$

\section{Figure 3A}

Study 3: Response Surface Plots Displaying the Associations of Accurate and Biased Perceptions of the Partner's Boredom with Perceiver Relationship Outcomes 

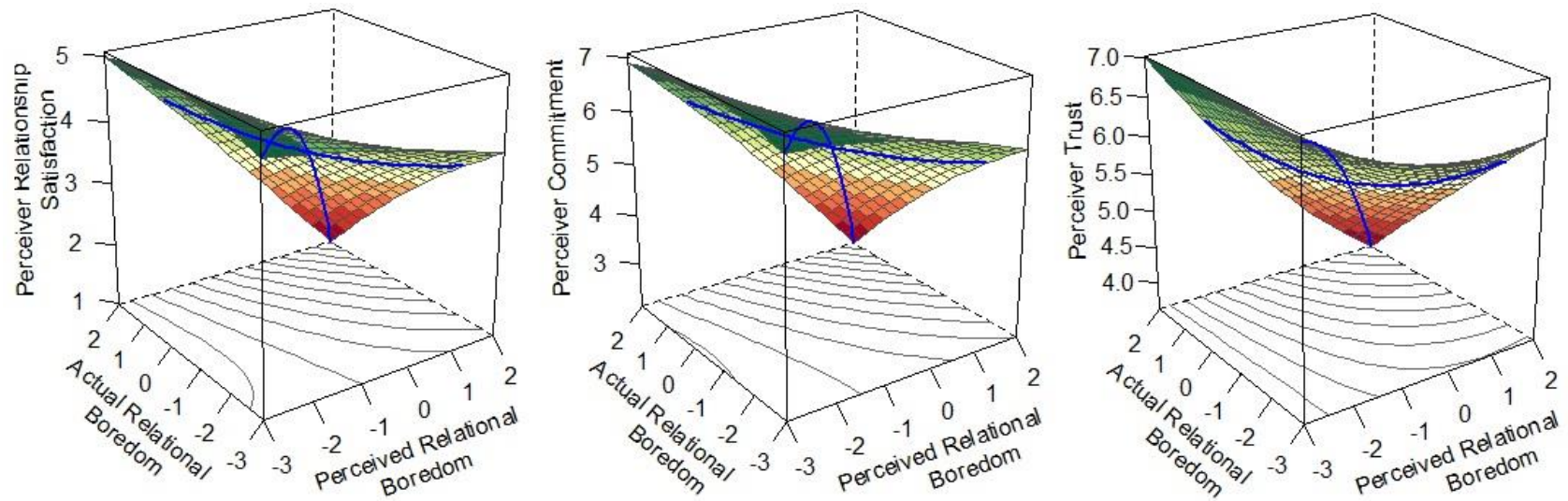

Note. The line of congruence runs from the front corner to the back corner, and the line of incongruence runs from the left corner to the right corner.

\section{Figure 3B}

Study 3: Response Surface Plots Displaying the Associations of Accurate and Biased Perceptions of the Partner's Boredom with Partner Relationship Outcomes
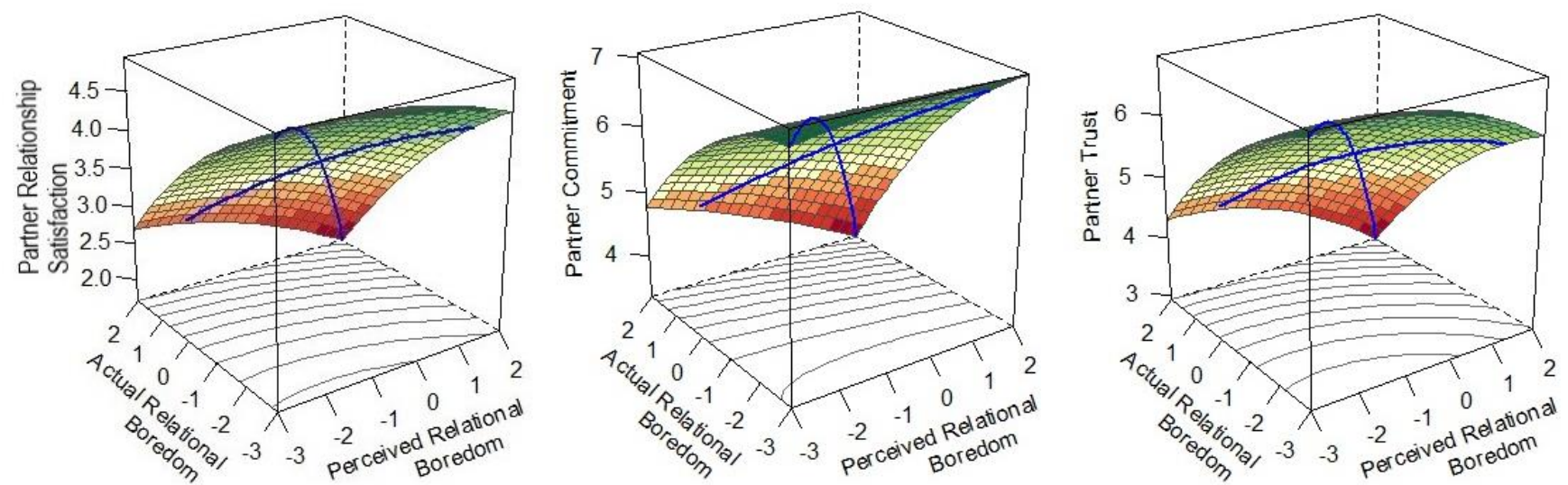

Note. The line of congruence runs from the front corner to the back corner, and the line of incongruence runs from the left corner to the right corner. 


\section{Exploratory Analyses}

\section{Does Accuracy and Bias in Boredom Perceptions Motivate Boredom Coping?}

In Study 3, we explored the lagged effects of accuracy and bias on perceivers' and partners' engagement in boredom coping behaviors. Specifically, we tested whether perceivers' overestimation of their partner's boredom on one day would be associated with perceivers enacting greater boredom coping behaviors the following day (i.e., if overestimating a partner's relational boredom might motivate future relationship maintenance behaviors). To test this, we used RSA as described above.

As seen in Table 5 and Figure 4, there were no effects for perceiver boredom coping for any surface value. For partners, inaccuracy (over- and under-estimation) was associated with greater boredom coping than accuracy, and partners engaged in more boredom coping behaviors the next day if their boredom was underestimated (vs. overestimated). Additionally, partners engaged in more coping behaviours when their boredom was accurately perceived at low (vs. high) levels.

These findings were insufficient in explaining the consistent links found in Studies 1-3 between perceivers' overestimation of their partner's boredom predicting partners' better relationship outcomes. However, given that partners' engagement in boredom coping behaviors was associated with perceiver accuracy and bias in these analyses, we then considered the possibility that boredom coping behaviors are not a reaction to perceived boredom, but a precursor to it. 


\section{Table 5}

Study 3: Associations of Accurate and Biased Perceptions of the Partner's Boredom with Boredom Coping Behaviors

\begin{tabular}{|c|c|c|c|c|}
\hline \multirow[b]{2}{*}{ Relationship Outcome } & \multicolumn{2}{|c|}{ Line of Congruence } & \multicolumn{2}{|c|}{ Line of Incongruence } \\
\hline & Slope $\mathrm{a}_{1}$ & Curvature a2 & Slope a3 & Curvature a4 \\
\hline Perceiver Boredom Coping & $-.13(.07)$ & $.02(.03)$ & $.13(.10)$ & $.10(.08)$ \\
\hline Partner Boredom Coping & $-.16(.07)^{*}$ & $-.001(.03)$ & $-.20(.09)^{*}$ & $.21(.07)^{* *}$ \\
\hline \multicolumn{5}{|c|}{ Note. $N_{\text {Study } 3}=115$ heterosexual couples. We report unstandardized coefficients, with standard errors } \\
\hline \multicolumn{5}{|l|}{ in parentheses. } \\
\hline${ }^{*} p<.05,{ }^{* *} p<.01$ & & & & \\
\hline
\end{tabular}

\section{Figure 4}

Study 3: Response Surface Plots Displaying the Associations of Accurate and Biased Perceptions of the Partner's Boredom with Perceiver and Partner Boredom Coping Behaviors
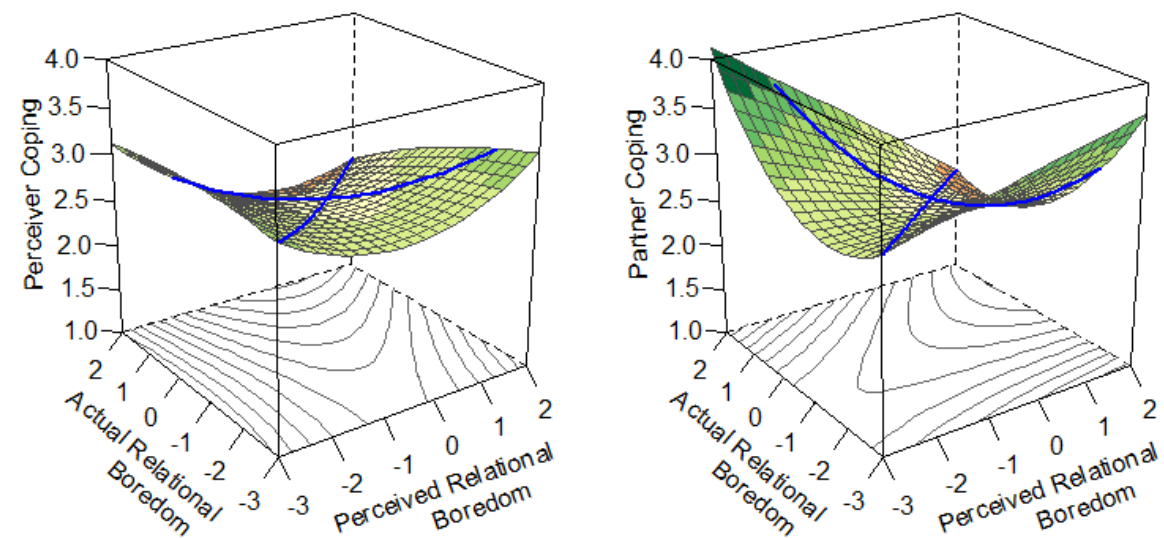

Note. The line of congruence runs from the front corner to the back corner, and the line of incongruence runs from the left corner to the right corner. 


\section{Do Boredom Coping Behaviors Serve as a Cue Guiding Boredom Perceptions?}

In our second series of exploratory analyses, we tested whether partners' boredom coping behaviors may serve as a cue that informs perceivers' judgments of their partner's boredom. To explore this idea, we tested two multilevel path models consistent with previous accuracy and bias research (e.g., Bolger \& Laurenceau, 2013; LaBuda et al., 2019). The first model tested the same-day effects of boredom coping behaviors on accuracy and bias (see Figure 5A), and the second model included lagged variables that tested whether boredom coping behaviors on a previous day predicted accuracy and bias the following day (see Figure 5B). These models were conducted at Level 1 (day), controlling for Levels 2 (person) and 3 (couple). In these models, perceivers' judgments of their partner's boredom were the outcome variable, predicted by the perceivers' own boredom and the partner's actual reported boredom. These variables were centered around the grand mean of all partners' boredom reports, consistent with the T\&B Model (West \& Kenny, 2011), to allow simultaneous testing of tracking accuracy, directional bias, and assumed similarity. We also included partners' boredom coping behaviors to determine whether perceivers rely on their partner's behaviors when making judgments of how bored they are with the relationship, and whether doing so improves their accuracy. If perceivers' and partners' relational boredom are associated with partners' boredom coping behaviors, this indicates that boredom coping behaviors are a relevant cue for boredom; if, in turn, partners' boredom coping behaviors predict perceivers' judgments of relational boredom, then it indicates that perceivers are indeed using these behaviors as a cue. 


\section{Figure 5A}

Study 3: Conceptual Exploratory Model Showing Truth and Bias Estimates with Partners' Boredom Coping Behaviors on a Given Day as a Cue the Same Day

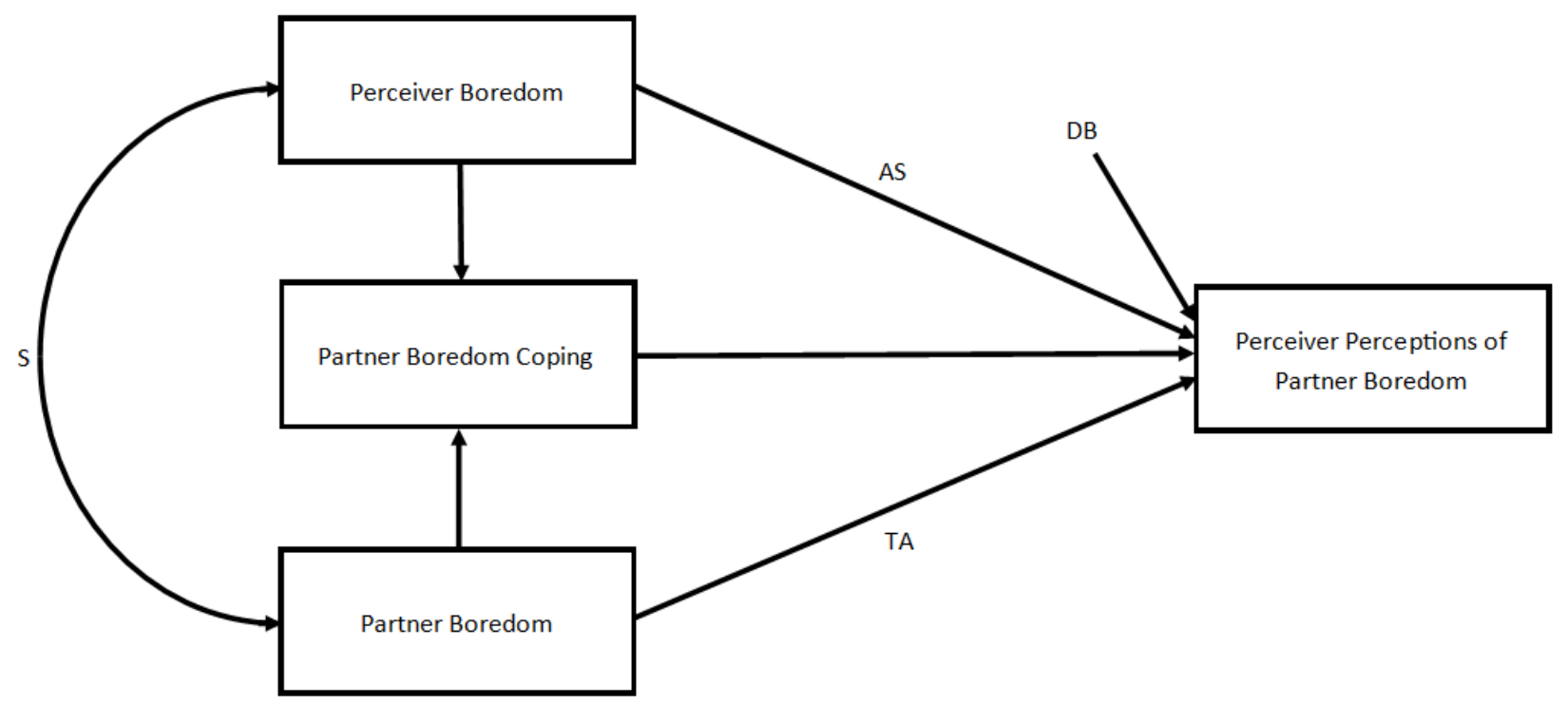

Note $\mathrm{S}=$ similarity; $\mathrm{AS}=$ assumed similarity; $\mathrm{TA}=$ tracking accuracy; $\mathrm{DB}=$ directional bias.

\section{Figure 5B}

Study 3: Conceptual Exploratory Model Showing Truth and Bias Estimates with Partners' Boredom Coping Behaviors on a Previous Day as a Cue the Following Day

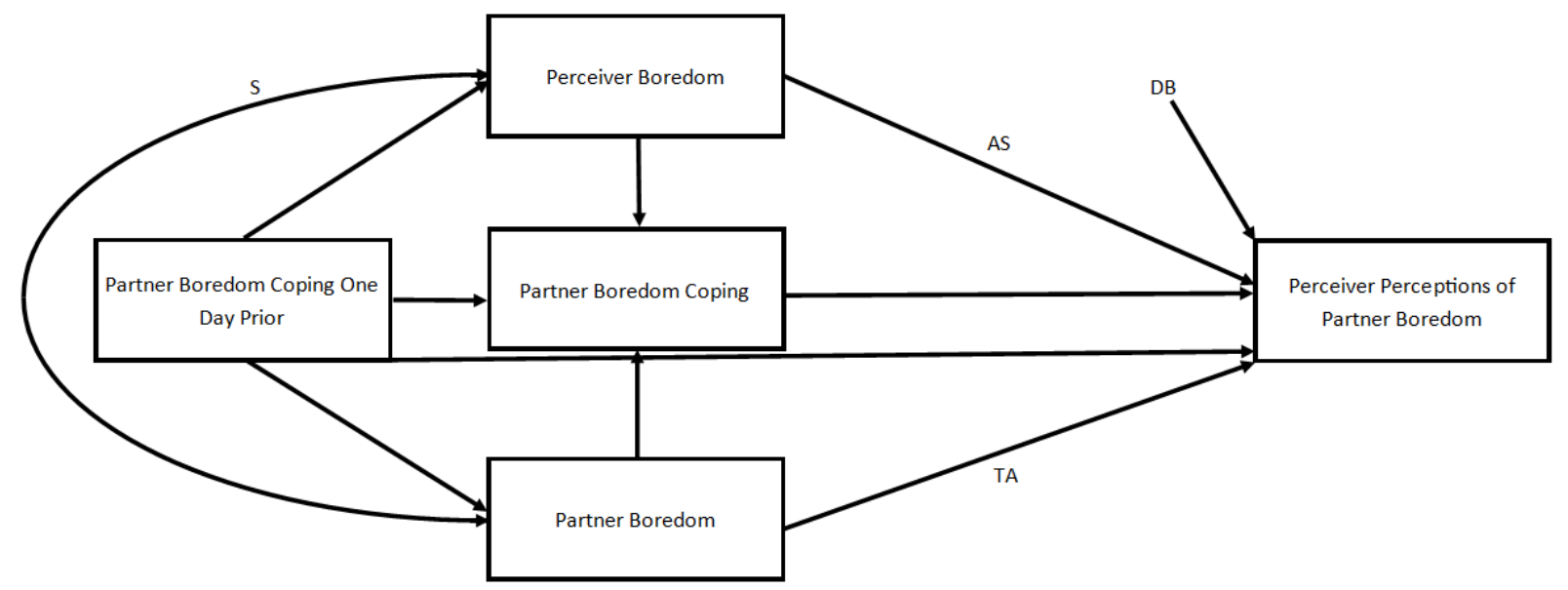

Note. $\mathrm{S}$ = similarity; $\mathrm{AS}$ = assumed similarity; $\mathrm{TA}$ = tracking accuracy; $\mathrm{DB}=$ directional bias. 
The results from our two models are displayed in Table 6. Findings from the first model revealed that greater partner boredom on a given day predicted fewer partner boredom coping behaviors the same day, meaning that partners' boredom coping behaviors were a relevant cue regarding actual relational boredom experiences. Perceivers' boredom was unrelated to partners' boredom coping behaviors, and, interestingly, partners' boredom coping behaviors were unrelated to perceivers' judgments of boredom. This suggests that, although partners' boredom coping behaviors are a relevant cue of how bored they are with the relationship, perceivers did not actually use these behaviors to inform their judgments.

Findings from the second model revealed that greater partner boredom coping behaviors the previous day predicted greater partner boredom coping and lower perceiver and partner boredom the next day. This demonstrates the enduring effects of partners' boredom coping behaviors, and also indicates that boredom coping behaviors on a prior day were a relevant cue for boredom experiences the next day. However, as in Model 1, prior-day partner boredom coping behaviors were unrelated to perceivers' judgments of boredom the next day, suggesting once again that perceivers did not respond to a relevant cue to their partner's boredom. 


\section{Table 6}

Study 3: Exploratory Model Results for Relational Boredom and Partner Boredom Coping Behaviors as Cues for Perceiver Accuracy and Bias

Path $\quad b(S E)$

\section{Model 1 (Same-Day)}

Similarity

Assumed Similarity

$.83(.06)^{* * *}$

Tracking Accuracy

$.18(.05)^{* * *}$

Directional Bias

$.11(.03)^{* * *}$

Perceiver Boredom $\rightarrow$ Partner Boredom Coping Behaviors

Partner Boredom $\rightarrow$ Partner Boredom Coping Behaviors

$-.37(.07)^{* * *}$

Partner Boredom Coping Behaviors $\rightarrow$ Perceiver Judgments of Boredom

$.01(.01)$

\section{Model 2 (Lagged)}

Similarity

$.68(.13)^{* * *}$

Assumed Similarity

$.84(.06)^{* * *}$

Tracking Accuracy

$.16(.05)^{* * *}$

Directional Bias

$.09(.03)^{* * *}$

Perceiver Boredom $\rightarrow$ Partner Boredom Coping Behaviors

Partner Boredom $\rightarrow$ Partner Boredom Coping Behaviors

$-.22(.05)^{* * *}$

Partner Boredom Coping Behaviors $\rightarrow$ Perceiver Judgments of Boredom

$.01(.01)$

Partner Boredom Coping 1 Day Prior $\rightarrow$ Perceiver Boredom Next Day

$-.14(.04)^{* * *}$

Partner Boredom Coping 1 Day Prior $\rightarrow$ Partner Boredom Next Day

$-.18(.04)^{* * *}$

Partner Boredom Coping 1 Day Prior $\rightarrow$ Partner Boredom Coping Next Day

$.48(.03)^{* * *}$

Partner Boredom Coping 1 Day Prior $\rightarrow$ Perceiver Judgments of Boredom Next Day

$.01(.01)$

Note. $N_{\text {Study } 3}=115$ heterosexual couples. We report unstandardized coefficients, with standard errors in parentheses.

$* * * p<.001$ 


\section{General Discussion}

Across three studies, we examined whether romantic partners are accurate and biased in their perceptions of each other's relational boredom, and whether their biased and (in)accurate perceptions were associated with relationship outcomes. Results revealed that romantic partners consistently overestimated each other's relational boredom, displayed significant tracking accuracy both across the features that comprise relational boredom (Studies 1-2) and across time (Study 3), and that people assumed similarity between their own experiences of relational boredom and their partner's. Additionally, accuracy and bias predicted relationship satisfaction, commitment, and trust, such that accurately perceiving high levels of boredom was associated with worse relationship quality for both perceivers and partners. However, perceivers' relationship quality consistently remained high if perceptions of the partner's boredom, the partner's actual reported boredom, or both were low. In other words, perceptions of and partner's actual relational boredom were negatively linked to perceiver's relationship satisfaction, commitment, and trust only when the partner's boredom was high and the perceiver accurately recognized it as high. For perceivers, bias was consistently unrelated to relationship outcomes (except for satisfaction in Study 3, where underestimation was better than overestimation). The protective effects of inaccuracy for partners' outcomes were less consistent. For partners, accurate perceptions of high relational boredom were consistently associated with worse relationship outcomes, and overestimation and accuracy at low levels of relational boredom were consistently associated with better relationship outcomes.

Underestimation, however, was associated with high levels of all partner outcomes in Study 1, only commitment in Study 2, and none of the outcomes in Study 3. Overall, overestimation (vs. underestimation) of partners' boredom by perceivers was 
consistently associated with higher relationship quality for partners. Finally, we found that perceivers' perceptions of and partners' actual relational boredom experiences were not associated with perceivers' engagement in boredom coping behaviours, and that although partners' boredom coping behaviours are a relevant cue of boredom, perceivers do not use this cue when making boredom judgments.

Although initially we anticipated that perceivers would generally underestimate their partner's boredom, erring in a manner that served a self-protective function, all three studies consistently showed that perceivers, in fact, overestimate their partner's boredom. Overestimation may thus serve a relationship-protective function by prioritizing the partner, a notion consistent with risk regulation theory (Murray et al., 2006, 2008). Moreover, the costs associated with overestimating a partner's boredom may be less severe than the costs associated with underestimating that boredom (cf. Haselton \& Buss, 2000). The self-protective security gained by underestimating is potentially a false sense of security, putting the relationship at risk by missing signals indicating that maintenance strategies are needed. Conversely, overestimation may lead the perceiver to invest more time and resources than necessary to maintain their relationship, which may make the partner happier as they enjoy the benefits of the perceiver's efforts. Additionally, we did not find any benefits of underestimation for perceivers or partners over and above accuracy at low levels of boredom, whereas there were consistent benefits for partners when perceivers overestimated their boredom. A general tendency to overestimate, therefore, likely reflects perceivers erring on the side of what is most beneficial to their partner and the relationship overall.

In all studies, partners displayed significant tracking accuracy when making judgments of each other's boredom. Tracking accuracy in this context likely provides the perceiver with information regarding whether they are meeting their partner's 
needs, while also protecting them from investing in a relationship that their partner finds unfulfilling. Thus, the motivation to accurately track a partner's relational boredom is likely beneficial to the risk regulation system, as it aids in both knowing when to maintain closeness and intimacy through relationship maintenance, and when there may be risk associated with maintaining the relationship, thus motivating selfprotection (Murray et al., 2006). Although tracking accuracy may serve a necessary balancing function between two opposing innate motivations, accuracy at high levels of relational boredom was consistently associated with worse relationship outcomes for both perceivers and partners. This is consistent with previous research examining the effects of empathic accuracy on romantic relationship satisfaction and stability in relationship-threatening situations (e.g., Sillars et al., 1984; Simpson et al., 1995). Although accuracy may offer opportunities to gain information regarding the state of a relationship, such insights in the context of a threat (e.g., when ascertaining that your partner is bored) may be painful and upsetting (Ickes \& Simpson, 1997). These results also extend previous research by demonstrating that accuracy in the context of a threat is also detrimental for perceivers' partners. Altogether, our findings indicate that accurately recognizing a partner's high levels of relational boredom may impede future relationship quality for both dyad members.

Although accuracy at high levels of boredom was associated with poorer relationship quality for both perceivers and their partners, perceiver relationship satisfaction, commitment, and trust were protected if perceivers believed their partner's boredom was low (whether accurate or not). This is consistent with our original rationale that, as high boredom represents a relationship threat, perceiving low levels of partner boredom would serve a self-protective function. This self-protection likely leads to greater feelings of security in the relationship, resulting in greater quality. 
Interestingly, perceiver relationship quality was also consistently preserved if their beliefs that their partner's boredom was high were unfounded (i.e., when they overestimated boredom). Thus, overestimation of relational boredom may not invoke strong, negative emotions consistent with overestimation of other types of threats (cf. Mathews \& MacLeod, 1994, 2002). Alternatively, it is possible that these emotions are experienced in response to boredom but that boredom threatening a relationship feels manageable, with partners believing there are workable solutions to the problem in comparison to other types of threats. Believing that the threat can be managed or changed may therefore protect relationship quality. Future research should examine the mechanism behind this protective effect of overestimation, such as a lack of negative affect, and determine whether these results remain when examined over time. That is, underestimating a partner's boredom may protect the self in the short-term but, as this bias is unlikely to result in corrective action, it may lead to relationship problems in the long-term. Similarly, overestimation in the long-term, and thus potentially experiencing anxiety and fear that the relationship may end, may wear perceivers down over time and cause problems later in the relationship.

In contrast to the effects for perceivers, only accuracy at low levels of partner boredom and perceiver overestimation were consistently associated with higher relationship quality for partners. We believed that the effects for overestimation might be because perceivers who believe their partner is bored enact more relationship maintenance behaviors, consistent with previous research suggesting that although boredom is unpleasant, it signals to individuals the need for behavioral or cognitive change (Clore et al., 2001; Elpidorou, 2014). We explored this possibility in Study 3, testing whether overestimation on a given day led to perceivers engaging in boredom coping behaviors later. However, we found no evidence that accuracy or bias were 
associated with differences in perceivers' engagement in boredom coping behaviors. This is consistent with recent findings suggesting that although people recognize that growth-enhancing behaviours (e.g. novelty) are beneficial for combating relational boredom, these beliefs are not consistently translated into behavioral intentions (Harasymchuk et al., 2017). In fact, Harasymchuk et al. (2017) found that prescriptive beliefs translated into behavioural intentions only when competing options were made salient or the task was specific. Therefore, high perceptions of the partner's boredom, and overestimation specifically, may predict greater boredom coping behaviors only in particular circumstances. It is also possible that although boredom coping behaviors may be the most effective means of diminishing boredom, these are not the behaviours partners actually engage in when they encounter boredom. Believing one's partner is bored may not lead perceivers to attempt to reduce this negative experience directly, but instead create other, unrelated positive experiences that might outweigh the negative, such as increasing affection, support, or sacrifice, which also benefit the relationship (e.g., Cramer, 2004; Horan \& Booth-Butterfield, 2010; Impett et al., 2014). Future research should examine when overestimation leads to boredom coping behaviors, as well as additional processes that may explain the consistent effect of overestimation being associated with greater partner relationship quality.

Study 3 revealed that engagement in boredom coping behaviors is a relevant cue of partner boredom, but perceivers do not appear to use this information to inform their boredom judgments. We propose two potential reasons for this: (1) Perceivers are aware these behaviors are relevant cues for their partner's relational boredom, but they fail to recognize when these behaviors are occurring; or (2) partners accurately perceive these behaviors but fail to recognize them as a relevant cue. These possibilities have important implications for how to aid romantic partners in perceiving and 
alleviating one another's boredom experiences and are readily amenable to future research.

Interestingly, the strongest predictor of perceivers' judgments of their partner's boredom across all three studies was their own boredom experiences (i.e., assumed similarity). This has implications for couples whose levels of boredom mismatch. That is, if perceivers assume their experiences are similar to their partner's but they are actually quite different, they may be inaccurately perceiving their partner's experiences. Our exploratory findings indicate a potential avenue through which mismatched partners may become more accurate perceivers. That is, if partners can learn how to accurately perceive boredom coping behaviors and to interpret them as a cue of their partner's boredom, this may assist them in reducing potential mismatch inaccuracies. Having accurate information in this domain gives partners the opportunity to make informed judgments regarding whether to prioritize closeness-promoting behaviours or to distance themselves from a relationship that their partner finds unfulfilling.

This research is not without limitations. We focus specifically on perceptions of boredom as they occur in heterosexual, monogamous romantic relationships, which limits the generalizability of our results. In addition, although we were able to examine whether partners accurately perceive fluctuations in each other's boredom across time, the time frame for Study 3 was short. It is possible that boredom fluctuates more over extended periods, with only small changes happening on a day-to-day basis. Thus, future research should examine whether partners can track one another's boredom across lengthier time periods, and across major life transitions, such as pre- and postmarriage, the transition to parenthood, or becoming empty nesters.

\section{Conclusion}


We present three studies addressing an important gap in the relational boredom literature by examining whether romantic partners' perceptions of each other's relational boredom are accurate and biased, and how this (in)accuracy is associated with their own and their partner's relationship quality. Our findings suggest that romantic partners are fairly accurate in their perceptions of each other's relational boredom, and that accuracy and bias are associated with differences in relationship quality, but the effects of bias differ for perceivers and their partners. Understanding the reasoning behind these effects may be the next step towards helping romantic couples understand how to maximize the long-term benefits and avoid the costs of accurate and biased partner perception in relationship threatening situations. 


\section{References}

Aron, A., \& Aron, E. N. (1986). Love and the expansion of self: Understanding attraction and satisfaction. New York: Hemisphere.

Bagheri, L., \& Milyavskaya, M. (2020). Novelty-variety as a candidate basic psychological need: New evidence across three studies. Motivation and Emotion, 44(1), 32-53. https://doi.org/10.1007/s11031-019-09807-4

Campbell, L., Overall, N. C., Rubin, H., \& Lackenbauer, S. D. (2013). Inferring a partner's ideal discrepancies: Accuracy, projection, and the communicative role of interpersonal behavior. Journal of Personality and Social Psychology, 105, 217 233.

Clark, M. S., Von Culin, K. R., Clark-Polner, E., \& Lemay, E. P., Jr. (2017). Accuracy and projection in perceptions of partners' recent emotional experiences: Both minds matter. Emotion, 17, 196-207.

Clore, G. L., Gasper, K., \& Garvin, E. (2001). Affect as information. In J. P. Forgas (Ed.), Handbook of affect and social cognition (pp. 121-144). Lawrence Erlbaum Associates, Publishers.

Cramer, D. (2004). Emotional Support, Conflict, Depression, and Relationship Satisfaction in a Romantic Partner. The Journal of Psychology, 138(6), 532-542. https://doi.org/10.3200/JRLP.138.6.532-542

Dobson, K., Campbell, L., \& Stanton, S. C. E. (2018). Are you coming on to me? Accuracy and bias in couples' perceptions of sexual advances. Journal of Social and Personal Relationships, 35(4), 460-484.

Edwards, J. R. (2002). Alternatives to difference scores: Polynomial regression analysis and response surface methodology. In F. Drasgow \& N. W. Schmitt (Eds.), 
Advances in measurement and data analysis (pp. 350 - 400). San Francisco: Jossey-Bass.

Elpidorou, A. (2014). The bright side of boredom. Frontiers in Psychology, 5, 1-4. https://doi.org/10.3389/fpsyg.2014.01245

Fletcher, G. J. O., \& Kerr, P. S. G. (2010). Through the eyes of love: Reality and illusion in intimate relationships. Psychological Bulletin, 136, 627-658. doi: $10.1037 / \mathrm{a} 0019792$

Gillen, N. R., Wohl, M. J. A., \& Harasymchuk, C. (2012, June). Transgression severity moderates the positive relationship between relational boredom and selfforgiveness. Paper Presented in the Advances in Measurement and Conceptualization in the Study of Forgiveness and Unforgiveness Symposium at the 73nd Annual Convention of the Canadian Psychological Association.

Hammond, M. D., \& Overall, N. C. (2013). Men's hostile sexism and biased perceptions of intimate partners fostering dissatisfaction and negative behavior in close relationships. Personality and Social Psychology Bulletin, 39(12), 1585-1599.

Harasymchuk, C., \& Fehr, B. (2010). A script analysis of relational boredom: Causes, feelings, and coping strategies. Journal of Social and Clinical Psychology, 29(9), 988-1019.

Harasymchuk, C., \& Fehr, B. (2012). Development of a prototype-based measure of relational boredom. Personal Relationships, 19(1), 162-181.

Harasymchuk, C., \& Fehr, B. (2013). A prototype analysis of relational boredom. Journal of Social and Personal Relationships, 30(5), 627-646.

Haselton, M. G., \& Buss, D. M. (2000). Error management theory: A new perspective on biases in cross-sex mind reading. Journal of Personality and Social Psychology, 78(1), 81-91. https://doi.org/10.1037/0022-3514.78.1.81 
Hendrick, S. S. (1988). A generic measure of relationship satisfaction. Journal of Marriage and Family, 50, 93-98.

Horan, S. M., \& Booth-Butterfield, M. (2010). Investing in affection: An investigation of affection exchange theory and relational qualities. Communication Quarterly, 58(4), 394-413. https://doi.org/10.1080/01463373.2010.524876

Ickes, W., \& Simpson, J. A. (1997). Managing empathic accuracy in close relationships. In W. Ickes (Ed.), Empathic accuracy (pp. 218-250). New York: Guilford Press.

Impett, E. A., Gere, J., Kogan, A., Gordon, A. M., \& Keltner, D. (2014). How sacrifice impacts the giver and the recipient: Insights from approach-avoidance motivational theory. Journal of Personality, 82(5), 390-401.

\section{https://doi.org/10.1111/jopy.12070}

Kelley, H. H., Holmes, J. G., Kerr, N. L., Reis, H. T., Rusbult, C. E., Van Lange, P. A. M. (2003). An atlas of interpersonal situations. New York, NY: Cambridge University Press. doi:10.1017/CB09780511499845

Kenny, D. A., \& Acitelli, L. K. (2001). Accuracy and bias in the perception of the partner in a close relationship. Journal of Personality and Social Psychology, 80(3), 439448.

Kenny, D. A., Kashy, D. A., \& Cook, W. L. (2006). Dyadic data analysis. New York, NY: Guilford Press.

LaBuda, J. E., Gere, J., \& Impett, E. A. (2019). Perceptions of a romantic partner's approach and avoidance motives: Accuracy, bias, and emotional cues. Journal of Personality and Social Psychology. https://doi.org/10.1037/pspp0000256

Mathews, A., \& MacLeod, C. (1994). Cognitive Approaches to Emotion and Emotional Disorders. Annual Review of Psychology, 45(1), 25-50.

\section{https://doi.org/10.1146/annurev.ps.45.020194.000325}


Mathews, A., \& MacLeod, C. (2002). Induced processing biases have causal effects on anxiety. Cognition \& Emotion, 16(3), 331-354.

\section{https://doi.org/10.1080/02699930143000518}

Muise, A., Stanton, S. C. E., Kim, J. J., \& Impett, E. A. (2016). Not in the mood? Men under(not over-) perceive their partner's sexual desire in established intimate relationships. Journal of Personality and Social Psychology, 110, 725-742.

Murray, S. L., Derrick, J. L., Leder, S., \& Holmes, J. G. (2008). Balancing connectedness and self-protection goals in close relationships: A levels-of-processing perspective on risk regulation. Journal of Personality and Social Psychology, 94(3), 429-459.

\section{https://doi.org/10.1037/0022-3514.94.3.429}

Murray, S. L., Holmes, J. G., \& Collins, N. L. (2006). Optimizing assurance: The risk regulation system in relationships. Psychological Bulletin, 132(5), 641-666.

Overall, N. C., Fletcher, G. J. O., \& Kenny, D. A. (2012). When bias and insecurity promote accuracy: Mean-level bias and tracking accuracy in couples' conflict discussions. Personality and Social Psychology Bulletin, 38, 642-655. doi:

\section{$10.1177 / 0146167211432764$}

Overall, N. C., \& Hammond, M. D. (2013). Biased and accurate depressive symptoms and daily perceptions within intimate relationships. Personality and Social Psychology Bulletin, 39(5), 636-650.

Page-Gould, E. (2016). Multilevel modeling. In J. T. Cacioppo, L. G. Tassinary, \& G. G. Berntson (Eds.), Handbook of psychophysiology (4th ed., pp. 662-678). Cambridge University Press.

Reissman, C., Aron, A., \& Bergen, M. R. (1993). Shared activities and marital satisfaction: Causal direction and self-expansion versus boredom. Journal of Social and 
Personal Relationships, 10(2), 243-254.

https://doi.org/10.1177/026540759301000205

Rempel, J. K., Holmes, J. G., \& Zanna, M. P. (1985). Trust in close relationships. Journal of Personality and Social Psychology, 49(1), 95-112.

Rusbult, C. E., Martz, J. M., \& Agnew, C. R. (1998). The investment model scale: Measuring commitment level, satisfaction level, quality of alternatives, and investment size. Personal relationships, 5(4), 357-387.

Shanock, L. R., Baran, B. E., Gentry, W. A., Pattison, S. C., \& Heggestad, E. D. (2010). Polynomial regression with response surface analysis: A powerful approach for examining moderation and overcoming limitations of difference scores. Journal of Business and Psychology, 25(4), 543-554.

Sillars, A. L., Pike, G. R., Jones, T. S., \& Murphy. M. A. (1984). Communication and understanding in marriage. Human Communication Research, 10, 317-350.

Simpson. J. A., Ickes, W., \& Blackstone. T. (1995). When the head protects the heart: Empathic accuracy in dating relationships. Journal of Personality and Social Psychology, 69, 629-641.

Venditti, M. C. (1980). How to be your own marriage counselor. New York: Continuum.

West, T. V., Dovidio, J. F., \& Pearson, A. R. (2014). Accuracy and bias in perceptions of relationship interest for intergroup and intragroup roommates. Social Psychological and Personality Science, 5(2), 235-242.

West, T. V., \& Kenny, D. A. (2011). The truth and bias model of judgment. Psychological Review, 118(2), 357-378.

Westgate, E. C. (2020). Why boredom is interesting. Current Directions in Psychological Science, 29(1), 33-40. https://doi.org/10.1177/0963721419884309 